\title{
Antimony isotopic composition in stream waters impacted by acid mine drainage
}

\author{
ELÉONORE RESONGLES ${ }^{1}$, RÉMI FREYDIER ${ }^{1}$, COLIN \\ FERRARI $^{1}$, GERARDO ZAMORA ECHENIQUE ${ }^{2}$ AND \\ CORINNE CASIOT $^{1}$
}

${ }^{1}$ Hydrosciences Montpellier, Université de Montpellier, CNRS, IRD

${ }^{2}$ Universidad Técnica de Oruro

Presenting Author: eleonore.resongles@umontpellier.fr

Acid mine drainage (AMD) generated by the oxidative dissolution of sulfidic ores is a global environmental issue causing long-term contaminations of surface waters and sediments with metals and metalloids. Metal isotopes are valuable geochemical tracers to better understand the processes involved in the transport of these contaminants in AMDimpacted streams and possibly identify contamination sources. Recent analytical developments allowed the precise measurement of antimony isotopic composition in natural samples. However, to date only few studies investigated the potential of $\mathrm{Sb}$ isotopes as tracers in mining-impacted environments.

In this study, we examined the variations of $\mathrm{Sb}$ isotopic composition in a AMD-impacted stream at the San José mine (Oruro, Bolivia). Samples of water and sediments were collected from the mine discharge in Oruro city down to the lake Uru-Uru located $\sim 15 \mathrm{~km}$ downstream. Metal and metalloid concentrations were determined and $\mathrm{Sb}$ isotopic composition was measured by HG-MC-ICP-MS after Sb separation from the sample matrix [1].

The mine effluent exhibited a low $\mathrm{pH}(\sim 1-2)$, high dissolved Fe concentration $(3 \mathrm{~g} / \mathrm{L})$ and extreme $\mathrm{Sb}$ concentrations both in water $(7.8 \mathrm{mg} / \mathrm{L})$ and in sediments $(14.5 \mathrm{mg} / \mathrm{g})$. Sb isotopic composition was higher in the dissolved phase $\left(\dot{o}^{123} \mathrm{Sb}=0.46 \%\right.$ ) than in sediments $\left(\mathrm{o}^{123} \mathrm{Sb}=-0.09 \%\right.$ ) suggesting that the oxidative dissolution of sulfides preferentially releases heavy $\mathrm{Sb}$ isotope. A decrease in dissolved $\mathrm{Sb}$ concentration down to $10 \mu \mathrm{g} / \mathrm{L}$ occurred along the stream as a result of natural attenuation processes and was accompanied by a slight increase in isotopic composition $\left(\mathrm{o}^{123} \mathrm{Sb}=0.60 \%\right.$ ). An apparent fractionation of $+0.35 \%$ was observed between the solution and sediments which is similar to the fractionation factor determined during $\mathrm{Sb}^{\mathrm{V}}$ adsorption onto ferrihydrite in laboratory experiment (ongoing work) suggesting that adsorption may be an important process leading to an enrichment in heavy Sb isotope in AMD waters.

These results indicate that $\mathrm{Sb}$ isotopes may be useful to investigate the mechanisms controlling $\mathrm{Sb}$ fate in miningimpacted rivers. However, further laboratory experiments are required to better characterize $\mathrm{Sb}$ isotopic fractionation associated with independent processes including sulfide dissolution, biotic and abiotic redox reactions and $\mathrm{Sb}$ adsorption onto newly formed solid phases.

[1] Ferrari et al. (2021). JAAS, in press, https://doi.org/10.1039/D0JA00452A 